\title{
Analisis Kesesuaian Lahan Budidaya Tanaman Kayu Putih (Melaleuca leucadendra) di Kecamatan Bukit Batu Kota Palangka Raya Provinsi Kalimantan Tengah
}

\author{
Ermal Subhan ${ }^{1}$, Martwein R. Benung ${ }^{2}$ \\ ${ }^{1}$ Dinas ESDM Provinsi Kalimantan Tengah \\ ${ }^{2}$ Dinas ESDM Provinsi Kalimantan Tengah \\ Surel: ${ }^{1}$ ermal_subhan@pasca.upr.ac.id; ${ }^{2}$ dede.benung@gmail.com
}

\section{ABSTRAK}

Salah satu lokasi yang menghasilkan produksi tanaman kayu putih (Melaleuca leucadendra) di Kalimantan Tengah adalah Kecamatan Bukit Batu. Pemasaran tanaman kayu putih oleh masyarakat tidak terlalu sulit, karena tersedia perusahaan yang akan menampung dan membeli hasil budidaya tanaman masyarakat. Permasalahannya adalah pertumbuhan tanaman kayu putih tidak merata. Perlu dilakukan upaya yaitu melakukan kajian kesesuai lahan. Tujuan penelitian ini adalah untuk mengetahuai apakah tanaman kayu putih sesuai dengan kondisi lahan di Kecamatan Bukit Batu. Metode penelitian yang digunakan deskriptif kuantitatif. Hasil kesesuaian lahan tanaman kayu putih tergolong sesuai marginal faktor pembatas $\mathrm{C}$ organik $\left(\mathrm{S}_{3}\right)$ dan tidak sesuai $\mathrm{N}$ dengan faktor pembatas $\mathrm{pH}$ $\left(\mathrm{H}_{2} \mathrm{O}\right)$, tekstur pasir sulit untuk diatasi atau tidak dapat diatasi.

\section{Kata kunci}

Kayu putih, Kesesuaian lahan, Bukit batu.

\section{PENDAHULUAN}

Di wilayah banyak terdapat lahan yang tidak dimanfaatkan dan dibiarkan begitu saja, sehingga kondisi lahan dalam keadaan terbuka yang telah ditutupi tumbuhtumbuhan yang tidak produktif seperti alang-alang dan semak belukar. Lahan tidur merupakan salah satu hasil kegiatan masyarakat yang melakukan ladang berpindah atau pertanian padi semusim dan biasanya setelah panen maka lahan tersebut ditinggalkan dan masyarakat berpindah mencari lahan yang baru untuk berladang dan menanam padi kembali. Budaya ladang berpindah sudah dilakukan secara turun menurun sehingga di wilayah Kalimantan Tengah terdapat banyak lahan tidur yang dibiarkan begitu saja. Salah satu perusahaan yang bergerak di bidang perkebunan telah manfaatkan lahan tidur dengan melakukan budidaya tanaman kayu putih.

Tanaman kayu putih mampu tumbuh dengan baik pada lahan-lahan marginal maupun di daerah rawa-rawa dan genangan air, mampu beradaptasi pada tanah dengan drainase jelek, tahan terhadap kebakaran dan toleransi terhadap tanah dengan kadar garam rendah sampai dengan yang tinggi. Kayu putih dapat tumbuh pada berbagai kondisi tapak, di dataran tinggi maupun rendah yang berbatasan dengan hutan pantai dan tumbuh secara monokultur. Selain itu, kayu putih tahan terhadap suhu panas dan kebakaran. Kayu putih dapat hidup dan tumbuh kembali selama 1 tahun dengan kondisi daun-daun yang sudah dapat dipetik. Akar kayu putih terdiri atas akar 
tunggang, akar lateral, dan akar sekunder. Akar tunggang lurus dan tumbuh ke bawah, sedangkan akar lateral tumbuh pada leher akar pada awal pertumbuhan. Akar sekunder menyebar pada kedalaman sekitar $20 \mathrm{~cm}$ di bawah permukan tanah ${ }^{[1]}$.

Tanaman kayu putih dapat digolongkan ke dalam tanaman yang dapat bertahan hidup pada kondisi lahan yang kurang subur, dengan iklim kering yang panjang, tahan terhadap suhu udara panas. Tanaman ini dapat ditemukan dari dataran rendah sampai pada ketinggian $400 \mathrm{~m}$ dpl., dapat tumbuh di dekat pantai di belakang hutan bakau, dengan tektur dari lempung berliat sampai liat berlempung, pada $\mathrm{pH}$ 47. Tanaman kayu putih ideal tumbuh pada iklim kering, curah hujan maksimum 2000 $\mathrm{mm}$ pertahun dengan suhu minimum $22^{\circ} \mathrm{C}$ dan suhu maksimum $32^{\circ} \mathrm{C}(3,4)$. Tanaman kayu putih mempunyai daur biologis yang panjang, cepat tumbuh, dapat tumbuh subur pada tanah dengan draenase baik maupun jelek, dengan kadar garam tinggi maupun asam, tanaman kayu putih dapat dimanfaatkan sebagai tanaman penghijauan pada lahan dengan kemiringan kurang dari $15 \%{ }^{[2]}$.

Dengan percontohan perkebunan tanaman kayu putih tersebut, masyarakat mulai ikut memanfaatkan lahan-lahan tidur menjadi perkebunan tanaman kayu putih sekarang lahan yang semula tidak bermanfaat menjadi lahan yang produktif sehingga dapat bermanfaat bagi perekonomian setempat. Di Kalimantan Tengah salah satu lokasi yang menghasilkan produksi tanaman kayu putih adalah di Kecamatan Bukit Batu dari segi pemasaran masyarakat tidak terlalu susah karena perusahaan tanaman kayu putih yang akan menampung dan membeli hasil budidaya tanaman masyarakat.

Sofyan $^{[3]}$ mengatakan bahwa karakteristik lahan adalah sifat-sifat pengenalan atau atribut dari sebidang tanah. Data yang dibutuhkan dalam mengevaluasi lahan yaitu: peta topografi, peta tanah, data iklim dan curah hujan. Evaluasi lahan dilakukan dengan membandingkan karakteristik lahan dengan syarat tumbuh tanaman. Agar tanaman baik pertumbuhannya, maka perlu dilakukan kesesuaian lahan terhadap jenis tanaman. Evaluasi dengan membedakan kelas lahan yang tergolong sesuai ( $\mathrm{S}=$ Suitable) dan tidak sesuai $(\mathrm{N}=\mathrm{Not}$ Suitable). S1 = Sangat sesuai, mempunyai faktor pembatas tidak berarti. S2 = Cukup sesuai, faktor pembatas berpengaruh terhadap produktivitasnya. S3 = Sesuai marginal, faktor pembatas masih dapat diatasi berat. $\mathrm{N}=$ Tidak sesuai, factor pembatas sangat berat atau sulit diatasi. Untuk mengetahui bagaimana kesesuaian lahan, menggunakan tanaman kayu putih.

Penelitian ini dilakukan untuk mengetahuai apakah tanaman kayu putih sesuai dengan kondisi lahan di Kecamatan Bukit Batu. Diharapkan hasil penelitian ini bermanfaat sebagai acuan masyarakat untuk membudidayakan tanaman kayu putih disesuaikan dengan kondisi lahan setempat.

\section{METODE PENELITIAN}

\section{Lokasi Penelitian}

Penelitian dilakukan di lokasi perkebunan kayu putih yang dibudidayakan oleh masyarakat di Kecamatan Bukit Batu Kota Palangka Raya Provinsi Kalimantan Tengah sebagaimana dapat dilihat dalam Gambar 1. 


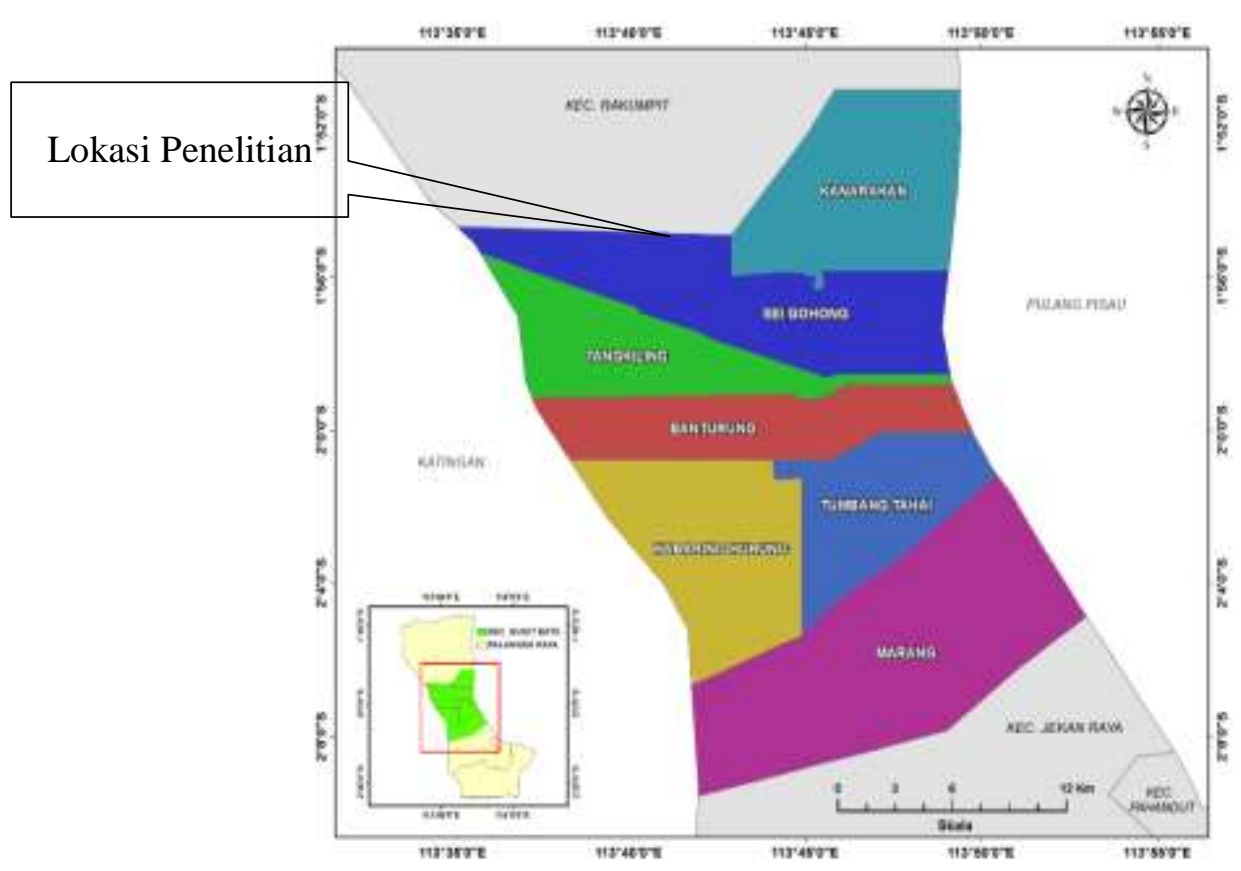

Gambar 1. Lokasi Penelitian

\section{Alat dan Bahan}

Alat yang digunakan adalah kantong sampel tanah, Global Positioning Sistem (GPS) Navigasi, kompas geologi, clinometer, cangkul, meteran, bor tangan, cetok, botol, kertas label, spidol permanen, box sampel, parang, sepatu boots, perlengkapan safety di lapangan, kamera untuk mendokumentasi kegiatan penelitian dan alat tulis lainnya. Bahan yang digunakan dalam penelitian ini adalah sampel tanah di pada perkebunan kayu putih di Kecamatan Bukit Batu..

\section{Pelaksanaan Penelitian}

Penelitian ini merupakan penelitian lapangan, dilaksanakan dengan menggunakan metode kuantitatif, kualitatif dan deskriptif dengan menggunakan survei atau pengamatan langsung untuk pengumpulan data dan informasi yang dibutuhkan. Penelitian deskriptif merupakan penelitian yang bertujuan memaparkan atau mendeskripsikan suatu fenomena dengan harapan menghasilkan gambaran akurat tentang fenomena, mekanisme sebuah proses, dan menjelaskan seperangkat tahapan atau proses. Tahapan penelitian bersumber dari data primer dan sekunder tahapan penelitian, secara lengkap tahapan penelitian dijelaskan di bawah ini.
Penelitian dilakukan meliputi 2 (dua) tahapan yaitu tahap pertama pengumpulan data sekunder, dan tahap kedua pengumpulan data primer dan analisis data. Metode penelitian yang berkaitan erat dengan tujuan penelitian ini, masing-masing metode analisis dijabarkan sebagai berikut.

\section{Metode Analisis Kesesuaian Lahan Metode Deskriptif Kuantitatif}

Metode ini digunakan untuk melakukan pengukuran kelerengan dan pengamatan kondisi batuan dan singkapan batuan. Untuk mendapatkan data sifat fisik dan kimia tanahnya dilakukan dengan cara sebagai berikut: a) menentukan titik pengambilan sampel tanah dilakukan dengan cara purposive sampling sebanyak 4 (empat) titik pengamatan; b) pada setiap titik pengamatan diambil sampel tanahnya pada lapisan olah pada kedalaman antara $0-20 \mathrm{~cm}$ dengan menggunakan ring sample untuk tanah utuh. Sedangkan tanah yang terganggu dilakukan dengan cara komposit, yakni contoh tanah diambil dengan jarak masing-masing \pm 1 (satu) meter searah mata angin, kemudian dicampur serta diaduk secara merata (dikompositkan). Selanjutnya diambil sebanyak kurang lebih 1(satu) kg untuk dianalisis di laboratorium; dan c) sebanyak 2 (dua) sampel tanah yang telah diambil 
kemudian dianalisis di laboratorium yang bersertifikat parameter yang diteliti yaitu sifat fisik tanah (tekstur), sifat kimia tanah $\mathrm{P}_{2} \mathrm{O}_{5}, \mathrm{pH}, \mathrm{C}$ - organik, N-total, P-tersedia, $\mathrm{K}$, $\mathrm{Ca}, \mathrm{Mg}, \mathrm{Fe}, \mathrm{Na},(\mathrm{dd}), \mathrm{Pb}, \mathrm{Cd}, \mathrm{Fe}, \mathrm{KB}$ dan KTK.

\section{Analisis Data}

Data pengukuran dan hasil analisis laboratorium kemudian dibandingkan dengan kriteria kesuburan tanah pada Pusat Penelitian Tanah Bogor 1984/1983 serta kriteria kesesuaian lahan untuk tanaman kayu putih ${ }^{[2]}$.

\section{HASIL DAN PEMBAHASAN}

Hasil kesesuaian tanaman kayu putih, diuraikan pada pembahasan berikut. Lokasi penelitian berada pada Kecamatan Bukit Batu Kota Palangka Raya Provinsi Kalimantan Tengah. Hasil analisis laboratorium sifat fisik tanah, sifat kimia tanah dan tingkat kesuburan tanah diuraikan di bawah ini.

\section{Sifat Fisik Tanah}

Hasil analisis sifat fisik tanah dilakukan pada analisis kelas tekstur tanah disajikan pada Tabel 1. Berdasarkan hasil analisis laboratorium menunjukkan bahwa kelas tekstur tanah di lokasi penelitian pada lokasi L.1 tergolong pasir dan lokasi L.2. tergolong pasir.

\section{Tabel 1. Klasifikasi Sifat Fisik Tanah}

\begin{tabular}{|c|c|c|c|c|}
\hline \multirow{2}{*}{ No. } & \multirow{2}{*}{$\begin{array}{c}\text { Parameter } \\
\text { Tekstur }\end{array}$} & \multirow{2}{*}{ Satuan } & \multicolumn{2}{|c|}{ Lokasi } \\
\hline & & & L.1. & L.2. \\
\hline 1. & Pasir & $\%$ & 95,58 & 91,54 \\
\hline 2. & Debu & $\%$ & 0,28 & 0,79 \\
\hline 3. & Clay & $\%$ & 4,14 & 7,68 \\
\hline
\end{tabular}

Klasifikasi Kelas Tekstur Tanah Pasir Pasir

Sumber : Data analisis Laboratorium (2018) dan Harjowigeno (1992).

Hasil analisis laboratorium (Tabel 1) menunjukkan bahwa kandungan pasir terendah pada Lokasi L.2 yaitu sebesar 91,54\% dan tertinggi pada lokasi L.1 yaitu sebesar 95,58\%. Kandungan debu terendah pada lokasi L.1 sebesar 0,28\% dan tertinggi pada lokasi L.2 sebesar 0,79\%. Unsur liat terendah pada lokasi L.1 sebesar 4,14\% dan tertinggi pada lokasi L.2 sebesar 7,68\%.

Distribusi ukuran partikel tanah pada Tabel 1 menunjukan bahwa ukuran partikel tanah di lokasi penelitian tidak memenuhi persyaratan untuk lahan pertanian yang mensyaratkan kisaran tekstur antara liat, lempung berdebu sampai lempung berpasir ${ }^{[4]}$. Jika dihubungkan dengan budidaya tanaman, tekstur tanah berpengaruh terhadap kemudahan dalam pengolahan tanah, ketersediaan air bagi tanaman, dan penentuan kebutuhan nitrogen bagi tanaman. Tanah yang bertekstur pasir, misalnya, mudah diolah namun kurang mampu menyediakan air bagi tanaman, kondisi sebaliknya terjadi pada tanah bertekstur liat, liat/lempung berdebu ${ }^{[5]}$. Jika dihubungkan dengan kebutuhan nitrogen, tanah dengan kandungan pasir kurang dari 65\% membutuhkan nitrogen antara 100 sampai $200 \mathrm{~kg} / \mathrm{ha}$, sedangkan apabila kandungan pasir di atas $70 \%$ maka nitrogen yang dibutuhkan lebih dari $200 \mathrm{~kg} / \mathrm{ha}^{[5]}$.

Kelas tekstur tanah (Tabel 1) pada lokasi penelitian yang tergolong pasir terdapat pada lokasi L.1. dan L.2. Tekstur tanah pasir menunjukkan bahwa di lokasi penelitian dominan pasir. Jenis tanah ini dapat dikategorikan tidak dapat menahan air dan miskin unsur hara. Hal ini disebabkan unsur hara di areal tersebut banyak terbawa air erosi karena berdasarkan hasil pengamatan di lapangan kemungkinan disebabkan lahan tersebut merupakan hasil sedimentasi pelarutan dari batuan induknya.

\section{Sifat Kimia Tanah dan Kesuburan Tanah}

Hasil analisis sifat kimia tanah di lokasi penelitian, dari sampel diketahui sangat bervariasi. Data hasil evaluasi kesuburan tanah di lokasi penelitian disajikan pada Tabel 2. 
Tabel 2. Hasil Evaluasi Kesuburan Tanah Lahan Bekas Penambangan Batubara

\begin{tabular}{|c|c|c|c|c|c|c|}
\hline \multirow{3}{*}{ No. } & \multirow{3}{*}{ Parameter } & \multirow{3}{*}{ Satuan } & \multicolumn{4}{|c|}{ Lokasi Penelitian } \\
\hline & & & Nilai & L.1 & Nilai & L. 2 \\
\hline & & & \multicolumn{4}{|c|}{ Harkat } \\
\hline 1 & KTK & $\mathrm{me} / 100 \mathrm{~g}$ & 24,71 & Sedang & 23,26 & Sedang \\
\hline 2 & $\mathrm{~KB}$ & $\%$ & 7,77 & Sangat Rendah & 4,41 & Sangat Rendah \\
\hline 3 & C-Organik & $\%$ & 1,79 & Sangat Rendah & 1 & Sangat Rendah \\
\hline 4 & $\mathrm{~N}$ & $\%$ & 0,25 & Sedang & 0,21 & Sedang \\
\hline 5 & K-dd & $\mathrm{me} / 100 \mathrm{~g}$ & 0,01 & Sangat Rendah & 0,01 & Sangat Rendah \\
\hline 6 & Ca-dd & $\mathrm{me} / 100 \mathrm{~g}$ & 1,16 & Sangat Rendah & 0,75 & Sangat Rendah \\
\hline 7 & Mg-dd & $\mathrm{me} / 100 \mathrm{~g}$ & 0,68 & Rendah & 0,23 & Sangat Rendah \\
\hline 8 & Na-dd & $\mathrm{me} / 100 \mathrm{~g}$ & 0,08 & Sangat Rendah & 0,05 & Sangat Rendah \\
\hline 9 & $\mathrm{pH}(\mathrm{H} 2 \mathrm{O})$ & - & 4,19 & Sangat Masam & 4,33 & Sangat Masam \\
\hline
\end{tabular}

Sumber: Hasil Evaluasi Peneliti (Pusat Penelitian Tanah Bogor, 1983)

Hasil evaluasi kesuburan tanah dari peneliti (Tabel 2) KTK (me/100gr) pada Lokasi L.1 dan Lokasi L.2 tergolong sedang. Kandungan KB (\%) pada lokasi L.1 dan lokasi L.2 tergolong sangat rendah. C-organik (\%) pada Lokasi L.1 dan lokasi L.2 tergolong sangat rendah. Kandungan unsur N (\%) pada Lokasi L.1 dan lokasi L.2 tergolong sedang. Kandungan K-dd (me/100gr) pada Lokasi L.1 dan Lokasi L.2 tergolong sangat rendah. Kandungan Ca-dd (me/100gr) pada Lokasi L.1 dan Lokasi L.2 tergolong sangat rendah. Kandungan Mg-dd (me/100gr) pada Lokasi L. 1 tergolong rendah, sedangkan Lokasi L.2 tergolong sangat rendah. Kandungan Na-dd (me/100gr) pada Lokasi L.1 dan Lokasi L2. tergolong sangat rendah. $\mathrm{pH}\left(\mathrm{H}_{2} \mathrm{O}\right)$ pada Lokasi L.1 dan Lokasi L.2 tergolong sangat masam.

Hasil evaluasi status kesuburan tanah pada lokasi penelitian kandungan unsur hara yang masih tergolong rendah sampai dengan sangat rendah dan upaya yang dilakukan adalah dengan memberikan pupuk NPK, $\mathrm{KCl}$ dan pupuk organik sesuai kebutuhan.

Hasil evaluasi status kesuburan tanah kandungan unsur $\mathrm{pH}$ tergolong sangat masam, dalam pengelolaan lahan lebih diperhatikan dan pelaksanaannya lebih ditingkatkan, khususnya pemberian kapur dan melakukan pemupukan sesuai dengan kebutuhan tanaman.

Tingkat kemasaman tanah pada lokasi penelitian termasuk kategori masam. Pada umumnya, batuan di banyak tambang secara alami mengandung sulfida yang dapat beroksidasi dan menimbulkan asam ketika bertemu oksigen dan air (Potentially Acid Forming/PAF). Akan tetapi bila batuan PAF dikelola dengan baik akan menurunkan risiko terjadinya air asam tambang (Acid Mine Drainage/AMD). Produksi asam dalam timbunan batuan bersulfida dapat dikendalikan dengan teknik pemilihan penutup. Prinsip penutupan tersebut yaitu menutup lapisan batuan PAF dengan lapisan batuan yang tidak berpotensi menimbulkan asam (Non Acid Forming/NAF). Di atas lapisan batuan NAF kemudian dihamparkan subsoil yaitu lapisan tanah yang mengandung sedikit bahan organik, kemudian dihamparkan topsoil, seperti diperlihatkan dalam gambar berikut ini. 


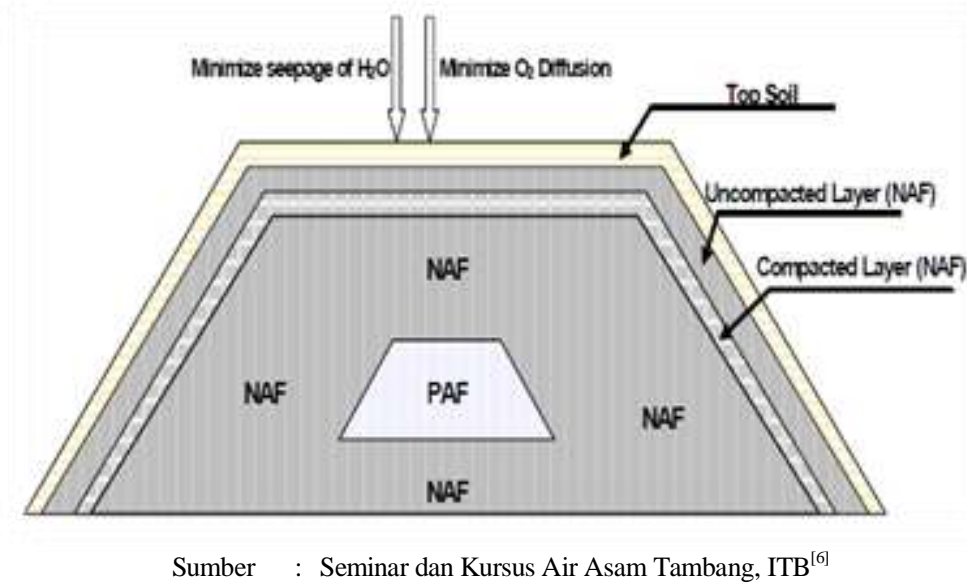

Gambar 2 Perlakuan terhadap PAF dan NAF

\section{Evaluasi Kesesuaian Lahan Budidaya Tanaman Kayu Putih}

Hasil pengamatan dan pengukuran pada lokasi penelitian mempunyai kedalaman efektif tanah berdasarkan hasil pengukuran lebih dari $100 \mathrm{~cm}$. Penampakan visual di lapangan tidak dijumpai singkapan batuan dan di permukaan lahan hampir jarang dijumpai batuan. Batuan jenis kerikil, krakal hanya dijumpai pada jalan-jalan untuk pengerasan. Kondisi kelerengan lahan agak landai, dengan hasil pengukuran kelerengan menggunakan clinometer berkisar antara $2 \%$ sampai $3 \%$.
Hasil pengambilan sampel tanah kemudian diuji di laboratorium yang menghasilkan analisis laboratorium sifat fisik dan kimia tanah serta berdasarkan pengamatan insitu di lapangan, kondisi lahan dapat digunakan untuk menentukan kesesuaian lahan di lokasi penelitian. Kriteria penilaian evaluasi kesesuaian lahan adalah untuk tanaman hutan yaitu tanaman kayu putih. Perbandingan data primer dan sekunder dengan kriteria penilaian evaluasi kesesuaian lahan untuk tanaman hutan, hasil analisis menunjukan kesesuaian lahan adalah untuk tanaman hutan tanaman kayu putih, sebagaimana disajikan dalam Tabel 3.

Tabel 3. Hasil Kesesuai Lahan Tanaman Kayu Putih

\begin{tabular}{|c|c|c|c|}
\hline \multirow{4}{*}{$\begin{array}{c}\text { Persyaratan } \\
\text { Karakteristik Lahan }\end{array}$} & PT. SEM Bartim & \multirow{2}{*}{\multicolumn{2}{|c|}{$\begin{array}{c}\text { Kesesuaian Lahan } \\
\text { Tanaman Hutan } \\
\text { Kayu Putih }\end{array}$}} \\
\hline & Hasil Pengamatan dan Analisis Lab. & & \\
\hline & Nilai & \multicolumn{2}{|c|}{ Lokasi Penelitian } \\
\hline & Rata-rata & L.1 & L. 2 \\
\hline Temperatur & & & \\
\hline Temperatur Rerata $\left({ }^{0} \mathrm{C}\right)$ & 21.46 & S.1 & S.1 \\
\hline Ketersediaan Air (w) & & & \\
\hline Curah hujan (mm) & 2.500 & S.1 & S. 1 \\
\hline Lamanya masa kering (bulan) & $3-4$ & S.1 & S. 1 \\
\hline Ketersedian oksigen (oa) & & & \\
\hline Drainase & Sangat Lambat & S.1 & S.1 \\
\hline Media perakaran (rc) & & & \\
\hline Tekstur & Pasir & $\mathrm{N}$ & $\mathrm{N}$ \\
\hline Kedalaman tanah (cm) & $>100$ & S.1 & S. 1 \\
\hline Retensi hara (nr) & & & \\
\hline pH H2O & 4.26 & $\mathrm{~N}$ & $\mathrm{~N}$ \\
\hline C-organik (\%) & 1,4 & S.3 & S.3 \\
\hline Hara tersedia (na) & & & \\
\hline
\end{tabular}


Tabel 3. (lanjutan) ...

\begin{tabular}{lccc}
\hline \multirow{2}{*}{$\begin{array}{c}\text { Persyaratan } \\
\text { Karakteristik Lahan }\end{array}$} & \multicolumn{2}{c}{ PT. SEM Bartim } & \multicolumn{2}{c}{ Kesesuaian Lahan } \\
\cline { 2 - 4 } & \multicolumn{2}{c}{ Hasil Pengamatan dan Analisis Lab. } & \multicolumn{2}{c}{ Kayu Putih } \\
\cline { 2 - 4 } & \multicolumn{2}{c}{ Nilai } & \multicolumn{2}{c}{ Lokasi Penelitian } \\
\cline { 2 - 4 } & Rata-rata & L.2 \\
\hline Hara tersedia (na) & $<8$ & S.1 & S.1 \\
Lereng (\%) & Ringan & S.1 & S.1 \\
Bahaya erosi & & & \\
Penyiapan lahan (lp) & $<3$ & S.1 & S.1 \\
Batuan di permukaan (\%) & $<2$ & S.1 & S.1 \\
Singkapan batuan (\%) & & & \\
\hline
\end{tabular}

Data hasil analisis kesesuaian lahan tanaman kayu putih disajikan pada Tabel 3. Parameter temperatur rerata $\left({ }^{\circ} \mathrm{C}\right)$ sebesar 21.46 pada Lokasi L.1 tergolong sangat sesuai S1, sedang pada Lokasi L.2 tergolong sangat sesuai S1. Parameter curah hujan rerata sebesar 2.500 (mm/tahun) pada Lokasi L.1 tergolong sangat sesuai S1, sedang pada Lokasi L.2 tergolong sangat sesuai S1. Parameter lamanya masa kering (bulan) rerata 3-4 bulan pada Lokasi L.1 tergolong sangat sesuai S1, dan pada Lokasi L.2 tergolong sangat sesuai S1. Parameter drainase (sangat lambat) pada Lokasi L.1 tergolong sangat sesuai S1, sedang pada Lokasi L.2 tergolong sangat sesuai S1. Parameter tekstur pasir pada Lokasi L.1 tergolong tidak sesuai N, sedang pada Lokasi L.2 tergolong tidak sesuai N.

Parameter kedalaman tanah $(\mathrm{cm})$ hasil pengamatan dan pengukuran di lapangan > $100 \mathrm{~cm}$, pada Lokasi L.1 tergolong sangat sesuai S1, sedang pada Lokasi L.2 tergolong sangat sesuai S1. Parameter C-organik sebesar $1,4 \%$ pada Lokasi L.1 tergolong sesuai marginal S3 sedang pada Lokasi L.2 tergolong sesuai marginal S3. Parameter $\mathrm{pH}$ $\mathrm{H}_{2} \mathrm{O}$ 4,26 (sangat masam) pada Lokasi L.1 tergolong tidak sesuai $\mathrm{N}$, sedang pada Lokasi L. 2 tergolong tidak sesuai $\mathrm{N}$.

Parameter lereng (\%) hasil pengamatan dan pengukuran di lapangan rerata kurang daripada $8 \%$, pada lokasi L1. tergolong sangat sesuai S1, dan pada lokasi L2. tergolong sangat sesuai S1. Parameter bahaya erosi hasil pengamatan dan pengukuran di lapangan tergolong ringan, pada lokasi L1. tergolong sangat sesuai S1, dan pada lokasi L2. tergolong sangat sesuai S1. Parameter batuan di permukaan (\%) hasil pengamatan kurang dari 3\%, pada lokasi L1. tergolong sangat sesuai S1, dan pada lokasi L2. tergolong sangat sesuai S1. Parameter singkapan batuan (\%) hasil pengamatan kurang dari $2 \%$, pada lokasi L1. tergolong sangat sesuai S1, dan pada lokasi L2. tergolong sangat sesuai $\mathrm{S} 1$.

Parameter untuk mengukur tingkat kesuburan tanah adalah nilai KTK dan $\mathrm{pH}$ tanah. Nilai KTK sangat tergantung pada kandungan liat, macam mineral serta bahan $\operatorname{organik}^{[7]}$. Untuk meningkatkan pertumbuhan tanaman diperlukan kondisi kemasaman tanah yang mendekati netral, sementara $\mathrm{pH}$ tanah di lokasi bekas pertambangan batubara tergolong masam. Untuk itu mutlak diperlukan pengapuran untuk meningkatkan $\mathrm{pH}$ tanah. Hal ini didukung oleh pendapat Sanchez ${ }^{[8]}$ bahwa tingkat kemasaman tanah ( $\mathrm{pH}$ tanah) berkaitan erat dengan kelarutan $\mathrm{Al}$ yang dapat menghambat pertumbuhan tanaman. Tanaman dapat tumbuh baik pada kisaran $\mathrm{pH} \quad 4,0$ sampai 8,5 meskipun pertumbuhan optimum akan dicapai pada kisaran $\mathrm{pH} 4,5$ sampai $8,0^{[4,9]}$.

\section{KESIMPULAN}

Hasil kesesuaian lahan tanaman kayu putih (Melaleuca leucadendra) tergolong sesuai marginal faktor pembatas $\mathrm{C}$ organic (S3) dan tidak sesuai $\mathrm{N}$ dengan faktor pembatas $\mathrm{pH}(\mathrm{H} 20)$, tekstur pasir sulit untuk diatasi atau tidak dapat diatasi

\section{SARAN}

Untuk tidak mengembangkan budidaya tanaman kayu putih dan alternatif yang dapat dilakukan yaitu membudidayakan tanaman lain seperti jambu mete yang sesuai dengan kondisi lahan kategori pasir. 


\section{REFERENSI}

[1] Sunarto, H., 2003, Budi Daya dan Penyulingan Кауи Putih. Yogyakarta, Penerbit Kanisius.

[2] Sudaryono, 2010, Evaluasi Kesesuaian Lahan Tanaman Kayu Putih Kabupaten Buru, Provinsi Maluku, Jakarta, Pusat Teknologi Lingkungan Badan Pengkajian dan Penerapan Teknologi.

[3] Sofyan, R., 2007, Evaluasi Kesesuaian Lahan dengan Contoh Peta Arahan Penggunaan Lahan Kabupaten Aceh Barat, Bogor, Balai Penelitian Tanah dan World Agroforestry Centra.

[4] Djaenuddin, dkk., 1994, Kriteria Kesesuaian Lahan Untuk Komoditas Petanian, Bogor, Badan Penelitian dan Pengembangan Pertanian Bogor.

[5] Hermawan, B., 2011, Peningkatan Kualitas Lahan Bekas Tambang Melalui Revegetasi dan kesesuaianya Sebagai Lahan Pertanian Tanaman Pangan, Prosiding, Seminar Nasional Budidaya Pertanian Pengendalian Alih Fungsi Lahan Pertanian.

[6] Institut Teknologi Bandung, 2014, Air Asam Tambang Ke-5 dan Pascatambang di Indonesia, Seminar dan Kursus, Bandung, Institut Teknologi Bandung.
[7] Adisoemarto, S., 1994, Dasar-dasar Ilmu Tanah, Jakarta, Erlangga.

[8] Sanchez, P. A., 1976, Properties and Management of Soil in the Tropics, Canada, John wiley and Sons.

[9] Islami, T., Utamo, W. H., 1995, Hubungan Tanah, Air dan Tanaman, Semarang, IKIP Semarang Press.

[10] Subhan, E., Salampak, Embang, A. E., Masliani, 2019, Analisis Tingkat Kesuburan Tanah Lahan Bekas Penambangan Batubara PT. Senamas Energindo Mineral Kabupaten Barito Timur Provinsi Kalimantan Tengah, MITL, 4(2), 34-40.

[11] Subhan, E., 2020, Kajian Revegetasi Lahan Bekas Penambangan Batubara Menggunakan Tanaman Hutan Studi Kasus PT. Senamas Energindo Mineral Kabupaten Barito Timur Kalimantan Tengah, Disertasi, Pascasarjana Program Doktor Ilmu Lingkungan Universitas Paalangka Raya. 